\title{
Improving Medical Handover: An SHO-Led Approach to Implementing A Formalized Handover System
}

\author{
Rachel Hallam, Kurun Kumar, Susan Akintunde, Opeyemi Akinnawonu, \\ Saba Mahmood, and Rabiu Momoh
}

\section{ABSTRACT}

Handover is a high-risk exercise. As the number of doctors in hospitals vary between shifts, continuity of care must be secured from many professionals down to a few. Literature has repeatedly shown that handover time is when the greatest number of medical errors occur [1]. Tasks may be inefficiently handover over, mis-represented or forgotten entirely. We have shared perspectives from a quality improvement (QI) project undertaken at the William Harvey Hospital, Kent, United Kingdom towards ensuring safe and smooth handover of medical tasks between shifts at the acute medical department in this hospital.

Keywords: Handover, medical shifts, patient safety, team communication.

\section{INTRODUCTION}

The British Medical Association (BMA) Junior Doctors Committee has provided doctors with astute guidelines: handover must have a designated time and place, have adequate supervision, and be aided with technologies as appropriate for the department [2]. NHS improvement committee further highlights what should be handed over, namely current inpatients with their risk level, location, status of their investigations/management and any proposed clinical management plans to be implemented during the shift [3].

\section{Handover at the William Harvey Hospital}

The medical ward cover evening shift takes place $5 \mathrm{pm}-$ $9 \mathrm{pm}$ on weekdays at the William Harvey Hospital. During this time, one SHO must cover at least 15 wards throughout
Submitted: October 20, 2021

Published: November 14, 2021

ISSN: 2593-8339

DOI: 10.24018/ejmed.2021.3.6.1114

\section{R. Hallam}

William Harvey Hospital, Kent, United Kingdom.

(e-mail: rachel.hallam3@nhs.net)

K. Kumar

William Harvey Hospital, Kent, United Kingdom.

(e-mail: kurun.kumar@nhs.net)

S. Akintunde

William Harvey Hospital, Kent, United Kingdom.

(e-mail: akintunde@nhs.net)

O. Akinnawonu

William Harvey Hospital, Kent, United Kingdom.

(e-mail: o.akinnawonu@nhs.net)

S. Mahmood

William Harvey Hospital, Kent, United

Kingdom.

(e-mail: saba.mahmood@nhs.net)

R. Momoh*

William Harvey Hospital, Kent, United

Kingdom.

(e-mail: rabiu.momoh@nhs.net)

*Corresponding Author the hospital. Day doctors leave the hospital 5-5:30 pm and must handover any outstanding jobs or sick patients over to the on-call SHO by means of the bleep system.

The high bleep burden incurred by doctors handing over was raised as an unsafe distraction by the SHO-led QIP team as this could hinder timely assessment of unwell patients out of hours. Furthermore, the handover itself via phone was felt to be of poor quality as the SHO would be constantly distracted by other bleeps.

As a result of this perceived need for change, a group of Senior House Officers (SHOs) were granted permission by the AMU MDM (Acute Medical Unit Multi-Disciplinary Meeting) to audit and make proposed changes to the $5 \mathrm{pm}$ handover system. 


\section{Strategy for ChAnge}

See the proposed timeline for change below:

- $\quad$ Pre-intervention audit $28^{\text {th }}$ Sept- $9^{\text {th }}$ Oct 2020.

- Intervention trial period 5th-16th Oct 2020

- Regular reminders to medics about changes to handover;

- Presentation of results $16^{\text {th }}$ Oct 2020 at the Acute Medical Unit (AMU) multi-disciplinary meeting (MDM) where the decision was made to continue the new handover system based on positive survey feedback and positive effects on bleep frequency.

- Post intervention audit $19^{\text {th }}-30^{\text {th }}$ Oct 2020.

- Indirect monitoring of handover without active intervention by the QI team.

\section{A. Methods}

- Quantitative assessment of workload during 5-9 pm shift using bleep frequency. Assessed using tally charts filled in by the on-call SHO.

- Qualitative assessment of staff opinion using a "GoogleForms" survey These were then used by the QIP team to formulate a handover intervention with feedback from the AMU MDM.

\section{INTERVENTIONS}

See poster used to advertise change in handover below.

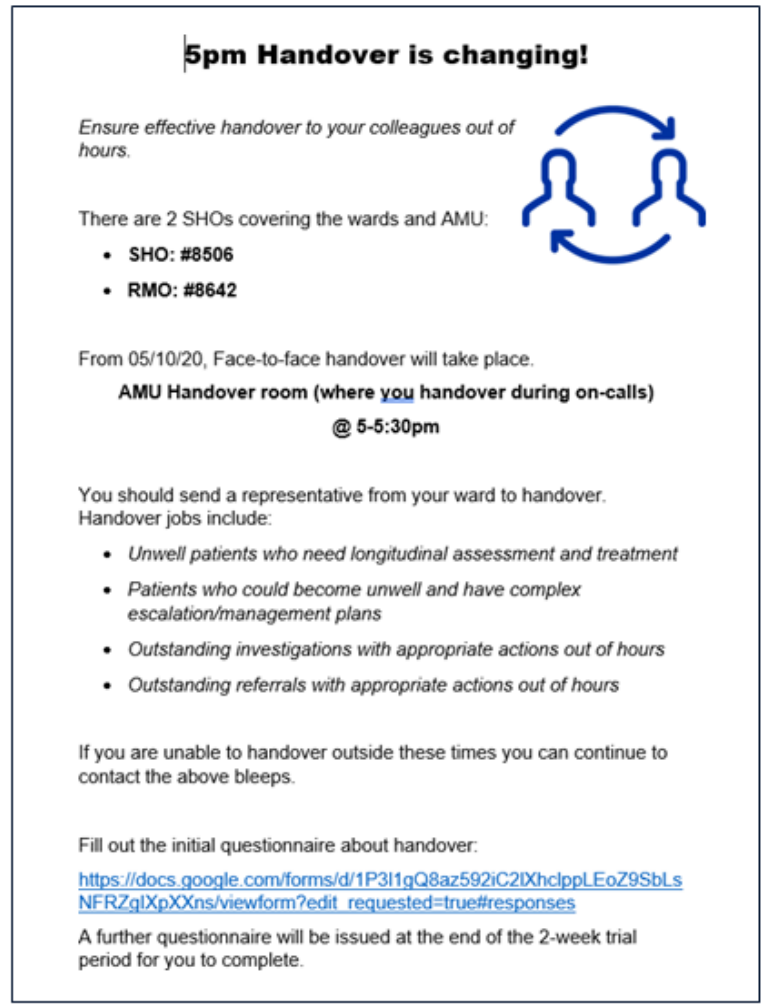

Fig. 1. Advert poster for change in handover modalities.

The interventions were five-fold:

- Staffing: formalize the RMO (Registered Medical Officer) role on ward cover so there are two doctors at handover and covering the wards after $5 \mathrm{pm}$.

- Designated handover time: Introduce a 5 pm- 5.30 pm face-to-face handover.

- Designated handover location with use of the Emergency Department Hub.
- Handover supervision: members of the QI team supervised handover among their peers during the 2week trial period.

- All junior medics were made aware of changes with the use of WhatsApp, emails, posters and word-of- mouth.

\section{RESULTS}

Initial auditing pre-intervention found that the SHO was bleeped on average 9.4 times per hour, the equivalent to once every 6 minutes. This was echoed in survey feedback where the most common suggestion related to extra staff being needed to cover the shift and complained of interruption of work by regular bleeps.

With the new handover system, total bleep frequency halved from 30 to 15 while charting of bleeps per hour displayed a change to front-loading of jobs rather than consistently throughout the shift (Fig. 1). Survey feedback showed enthusiasm for the new handover system, in particular the ability to discuss patients effectively without distraction. Enthusiasm for the system change was reflected in the post-intervention compliance with handover of $93 \%$, an improvement from the intervention period itself.

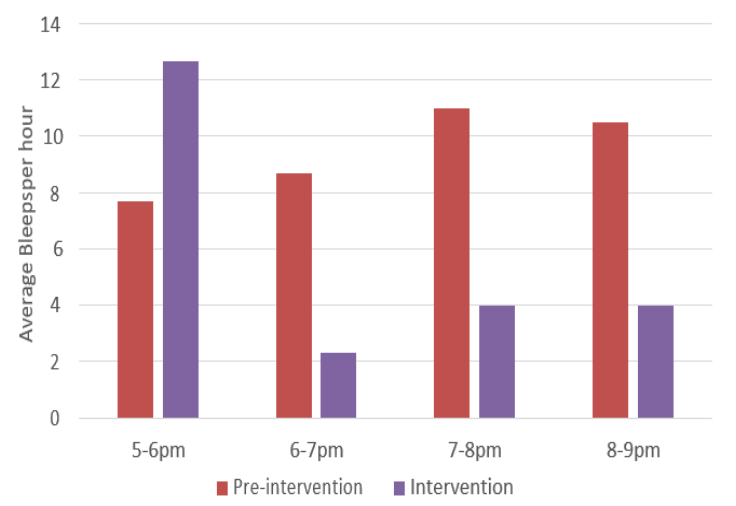

Fig. 2. Pre-intervention compared to post-intervention bleep frequency.

What format would you prefer for afternoon handover? 23 responses
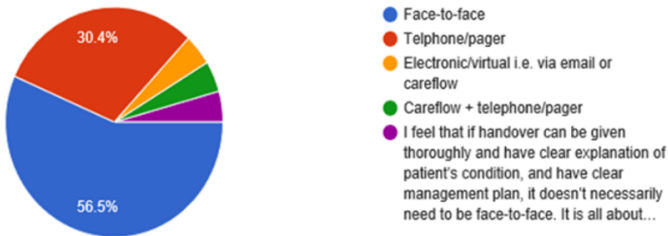

Fig. 3. Showing pie chart describing preferred handover formats.

TABLE I: SUMMARY OF OUTCOMES COMPARING STUDY PHASES. NB: POST-INTERVENTION DATA UNAVAILABLE DUE TO POOR COMPLIANCE IN FILLING OUT BLEEP SHEET BY ON-CALL SHOS

\begin{tabular}{ccccc}
\hline \hline & $\begin{array}{c}\text { Avg. No. Jobs } \\
\text { handed over } \\
5-5: 30 \mathrm{pm}\end{array}$ & $\begin{array}{c}\text { compliance } \\
\text { to new } \\
\text { handover }\end{array}$ & $\begin{array}{c}\text { Total } \\
\text { bleep 5-9 } \\
\text { pm }\end{array}$ & $\begin{array}{c}\text { Avg. Bleep } \\
\text { frequency } \\
\text { per hour }\end{array}$ \\
\hline \hline $\begin{array}{c}\text { Pre- } \\
\text { intervention }\end{array}$ & 8.3 & $0 \%$ & 30 & 9.4 \\
$\begin{array}{c}\text { Intervention } \\
\text { Post- }\end{array}$ & 6.8 & $91.3 \%$ & 15 & 7.5 \\
intervention & 6.2 & $93 \%$ & $\mathrm{n} / \mathrm{a}$ & $\mathrm{n} / \mathrm{a}$ \\
\hline \hline
\end{tabular}


See other qualitative feedbacks on the new face-to-face handover model in the figure below:

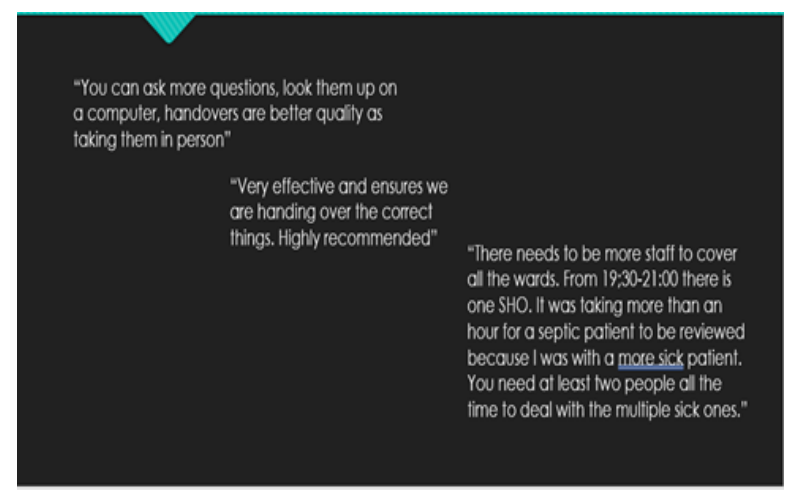

Fig. 4. Qualitative feedbacks on the new face-to-face handover model.

\section{LIMITATIONS}

- Lack of an objective measure of workload. IT were unable to track bleep frequency via switchboard, so it was necessary to self-monitor which is less accurate. It was also difficult to track the distribution of jobs between SHO and RMO during the intervention period.

- Surveys were subjective limited by the people who chose to respond.

- The RMO shift does not overlap with night-time handover.

- Lack of senior leadership was identified as a factor that could contribute to impaired handover efficiency and to not being able to sustain the change.

\section{FUTURE DiRECTION AND CONCLUSION}

Front-loading of jobs at the beginning of shift allowed the SHOs to prioritize jobs effectively. The addition of an RMO to the ward cover from 5-8 pm has improved workload. Day team doctors are now able to engage in undistracted handover which has improved confidence in patient safety.

This QI has been an exercise in communication with peers, consultants, and administration staff in order to cause a necessary change in protocol. The new handover system was proven to improve workload which ensures patient safety out of hours.

This shows that SHOs can effect meaningful change in the workplace: PSDA cycling provides the weight and evidence base to effect a bottom-up change that is sustained because it is wanted by the people who are implementing it. This Quality Improvement project continues to grow with the involvement of trainee-ACPs and registrars to continue to moderate and lead $5 \mathrm{pm}$ handover in line with BMA guidance.

\section{REFERENCES}

[1] Edmund SHK., Glenda C., Shannon W., Austin M., Calder L.A. Development and implementation of a standardized emergency department inter-shift handover tool to improve physician communication. BMJ open quality, 2020; 9(1): e000780.

[2] BMA Junior Doctors Committee, "Safe handover: Safe patients, guidance on clinical handover for clinicians and managers," (Accessed on: $\quad$ https://www.rcpch.ac.uk/sites/default/files/201802/bma_handover_college_tutors.pdf).
[3] NHS Improvement, "Implementing handovers and huddles: a framework for practice in maternity units," (Accessed on: https://www.pslhub.org/learn/patient-safety-in-health-andcare/transitions-of-care/handover/nhs-improvement-implementinghuddles-and-handovers- $\% \mathrm{E} 2 \% 80 \% 94$-a-framework-for-practice-inmaternity-units-25-march-2019-r136/). 